\title{
Association between MDM2 rs 2279744 polymorphism and breast cancer susceptibility: a meta-analysis based on 9,788 cases and II, 195 controls
}

Jie Gao ${ }^{1,2, *}$

An-Jing Kang,*

Shuai Lin',*

Zhi-Jun Dai'

Shu-Qun Zhang'

Di Liu'

Yang Zhao'

Peng-Tao Yang'

Meng Wang'

Xi-jing Wang'

'Department of Oncology,

${ }^{2}$ Department of Nephrology,

${ }^{3}$ Department of Pathology, The Second

Affiliated Hospital of Xi'an Jiaotong

University, Xi'an, People's Republic

of China

*These authors contributed equally to this work

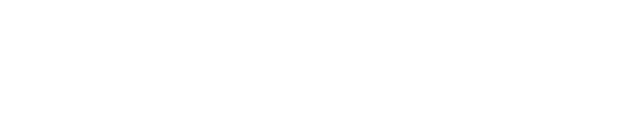

Purpose: Previous studies have suggested associations between MDM2 (mouse double minute 2 homolog) polymorphisms and cancer risk. The aim of this study was to evaluate the relationship between the MDM2 rs 2279744 polymorphism and the susceptibility of breast cancer.

Methods: We searched PubMed, Web of Knowledge, Embase, and the Chinese National Knowledge Infrastructure (CNKI) database for case-control studies published up to October 2013 that investigated MDM2 rs 2279744 polymorphism and breast cancer risk. Odds ratios (ORs) and 95\% confidence intervals (CIs) were used to assess the strength of these associations.

Results: A total of 19 studies were identified for the meta-analysis, including 9,788 cases and 11,195 controls. The variant heterozygote (TG) was associated with breast cancer risk in the overall population (TG vs TT: $\mathrm{OR}=1.10,95 \% \mathrm{CI}=1.04-1.17, P=0.001, P=0.23$ for heterogeneity test). In the subgroup analyses by ethnicity, a significantly increased risk was observed among Asians ( G vs T: OR $=1.12,95 \% \mathrm{CI}=1.02-1.23, P=0.02, P_{\text {het }}=0.04$; GG vs TT: $\mathrm{OR}=1.29$, $95 \% \mathrm{CI}=1.06-1.56, P=0.01, P_{\text {het }}=0.04$; TG vs TT: OR $=1.36,95 \% \mathrm{CI}=1.15-1.60, P=0.0004$, $P_{\text {het }}=0.45$; dominant model TG+GG vs TT: $\mathrm{OR}=1.21,95 \% \mathrm{CI}=1.03-1.41, P=0.02, P_{\text {het }}=0.07$ ). However, among Caucasians, rs 2279744 was associated with breast cancer risk in only one genotype (TG vs TT: OR $=1.09,95 \% \mathrm{CI}=1.00-1.18, P=0.04, P_{\text {het }}=0.37$ ). No publication bias was found in the present study.

Conclusion: This meta-analysis provides evidence for the association between the MDM2 rs 2279744 polymorphism and breast cancer susceptibility. The results suggest that the MDM2 rs 2279744 polymorphism plays an important role in breast cancer, especially in Asians.

Keywords: breast cancer, $M D M 2$, single nucleotide polymorphism, susceptibility, meta-analysis

\section{Introduction}

Breast cancer is one of the major cancers affecting morbidity and mortality of women worldwide. In the US, 232,340 new breast cancer cases were estimated in 2013; breast cancer comprises $29 \%$ of all new cancers in females. ${ }^{1}$ Breast cancer has a hereditary component and is insufficiently explained by high-penetrance genetic risk factors, such as $B R C A 1$ and $B R C A 2$ genes. ${ }^{2}$ Allele variants in oncogenes are candidate genetic risk factors that may alter breast cancer onset and outcome. Previous research has suggested that breast cancer results from multiple environmental factors, as well as genetic alterations, such as genetic polymorphisms. ${ }^{3,4}$ However, the exact molecular mechanisms of breast cancer still need intensive investigation.

\author{
Correspondence: Zhi-Jun Dai or \\ Xi-jing Wang \\ Department of Oncology, The Second \\ Affiliated Hospital of Xi'an Jiaotong \\ University, Xi'an, \\ People's Republic of China \\ Tel +862987679226 \\ Fax +86 2987679282 \\ Email dzj09। I@।26.com; \\ wangxj0613@I26.com
}

Therapeutics and Clinical Risk Management 2014:10 269-277 
p53 is a critical tumor suppressor gene that is commonly mutated in human cancers. ${ }^{5}$ MDM2 (mouse double minute 2 homolog), which encodes the protein located on chromosome 12 q13-14, is an important regulator of p53, and functions by suppressing p53 activity. ${ }^{6}$ Furthermore, MDM2 amplifications and overexpression have been considered an alternative mechanism of p53 inactivation in several human cancers. ${ }^{7}$ MDM2 is overexpressed in various cancers and leads to a worse prognosis in some cancers. ${ }^{8}$

A functional single nucleotide polymorphism (SNP) has been identified at position 309 within the first intron of the promoter region of the human MDM2 gene, and hence has been designated SNP309 (rs 2279744). ${ }^{9}$ Transversion of the $\mathrm{T}$ allele to the $\mathrm{G}$ allele in the region causes a higher affinity for the Sp1 transcription activator, and subsequently enhances the transcription of the MDM2 gene. SNP309 leads to an increase in the expression of MDM 2 mRNA and protein, and thereby attenuates the p53 response. ${ }^{9}$ In recent years, conflicting evidence has linked the SNP309G variant to enhanced risk of different cancer forms. ${ }^{10}$ The $M D M 2$ rs 2279744 polymorphism has been reported to be associated with some tumors, such as colon cancer, gastric carcinoma, and hepatocellular carcinoma. ${ }^{11-13}$ However, the association between rs 2279744 and breast cancer was inconsistent. ${ }^{14}$

Any single study is insufficient to confirm the association of the $M D M 2$ rs 2279744 polymorphism with the risk of breast cancer. This is particularly true for studies with relatively small sample sizes. ${ }^{15}$ It is important to accumulate data from different studies to provide evidence on the association of the $M D M 2$ polymorphism with breast cancer risk. To clarify the effect of the MDM2 rs 2279744 polymorphism on the risk of breast cancer, we carried out a meta-analysis on all eligible case-control studies to estimate the overall breast cancer risk of the MDM2 rs 2279744 polymorphism. Furthermore, we conducted the subgroup analysis by stratification according to ethnicity.

\section{Materials and methods Publication search}

Computer searches were carried out independently by two authors, in PubMed, Web of Knowledge, Embase, and the Chinese National Knowledge Infrastructure (CNKI) database (last search: October 15, 2013) to collect articles with casecontrol studies related to the association of the MDM2 rs 2279744 polymorphism and breast cancer risk.

The keywords were as follows: breast cancer/breast carcinoma/breast neoplasm, murine double minute 2/ MDM2, and polymorphism/genotype/SNP309/rs 2279744.
Furthermore, reference lists of the main reports and review articles were also reviewed by manual search to identify additional relevant publications.

\section{Selection criteria}

The following criteria were used to select studies to add to the meta-analysis: 1) case-control studies; 2) the studies evaluated the associations between the MDM2 rs 2279744 polymorphism and breast cancer risk; and 3) the studies included detailed genotyping data (total number of cases and controls, number of cases and controls with $\mathrm{T} / \mathrm{T}, \mathrm{T} / \mathrm{G}$, and $\mathrm{G} / \mathrm{G}$ genotypes).

Accordingly, the following exclusion criteria were also used: 1) the design of the experiments was not case-control; 2 ) the source of cases and controls, and other essential information were not provided; 3 ) the genotype distribution of the control population was not in accordance with the Hardy-Weinberg equilibrium (HWE); and 4) reviews and duplicated publications.

\section{Data extraction and synthesis}

Articles were reviewed independently by two authors and data with discrepancies in identification were discussed by all authors. For each included study, the following information was collected: first author, year of publication, country of origin, ethnicity, source of control, numbers of cases and controls, genotyping methods for MDM2 rs $2279744 \mathrm{~T} / \mathrm{G}$, and total number of cases and controls, as well as the number of cases and controls with $\mathrm{T} / \mathrm{T}, \mathrm{T} / \mathrm{G}$, and $\mathrm{G} / \mathrm{G}$ genotypes. Different ethnic ancestries were categorized as Caucasian, Asian, African, and "mixed". The "mixed" group means mixed or unknown populations. All the case and control groups were well-controlled. The non-cancer controls had no history of gynecologic disease, and there was no present evidence of gynecologic cancer, any malignant disease, or genetic disease. There were no statistically significant differences in terms of age distribution, smoking habits, or menstrual status between case and control groups. When studies included subjects of more than one ethnicity, genotype data were extracted separately according to ethnicities for subgroup analyses.

\section{Statistical analysis}

The associations between the MDM2 rs 2279744 polymorphism and breast cancer risk were measured by odds ratios (OR) with 95\% confidence intervals (CI). The significance of the pooled OR was determined by the $Z$-test. Statistical heterogeneity among studies was assessed with the $Q$ and $I^{2}$ statistics. The $Q$ test and $I^{2}$ test the variation 
which was due to heterogeneity or by random error. When the $P$-value of the heterogeneity tests was no more than 0.1 $(P \leq 0.1)$, we used the random effects model. When the $P$-value of the heterogeneity tests was more than $0.1(P \geq 0.1)$, we used the fixed effects model. Sensitivity analysis was also tested by removing one study at a time to calculate the overall homogeneity and effect size. Publication bias was evaluated by funnel plots and further assessed by Egger's linear regression test.

All statistical analyses were carried out with the review manager (RevMan 5.1 The Cochrane Collaboration, Oxford, UK) and Stata 10 software (Stata Corporation, College Station, TX, USA). All $P$-values in the meta-analysis were two-sided, and $P$-values less than 0.05 were considered significant.

\section{Results}

\section{Characteristics of studies}

As shown in Figure 1, a total of 31 records that fulfilled our search criteria were preliminarily identified for further detailed evaluation, which excluded 12 studies (Figure 1). Three studies were excluded because they were not case-control studies. Two studies were not focused on the association between the MDM2 rs 2279744 polymorphism

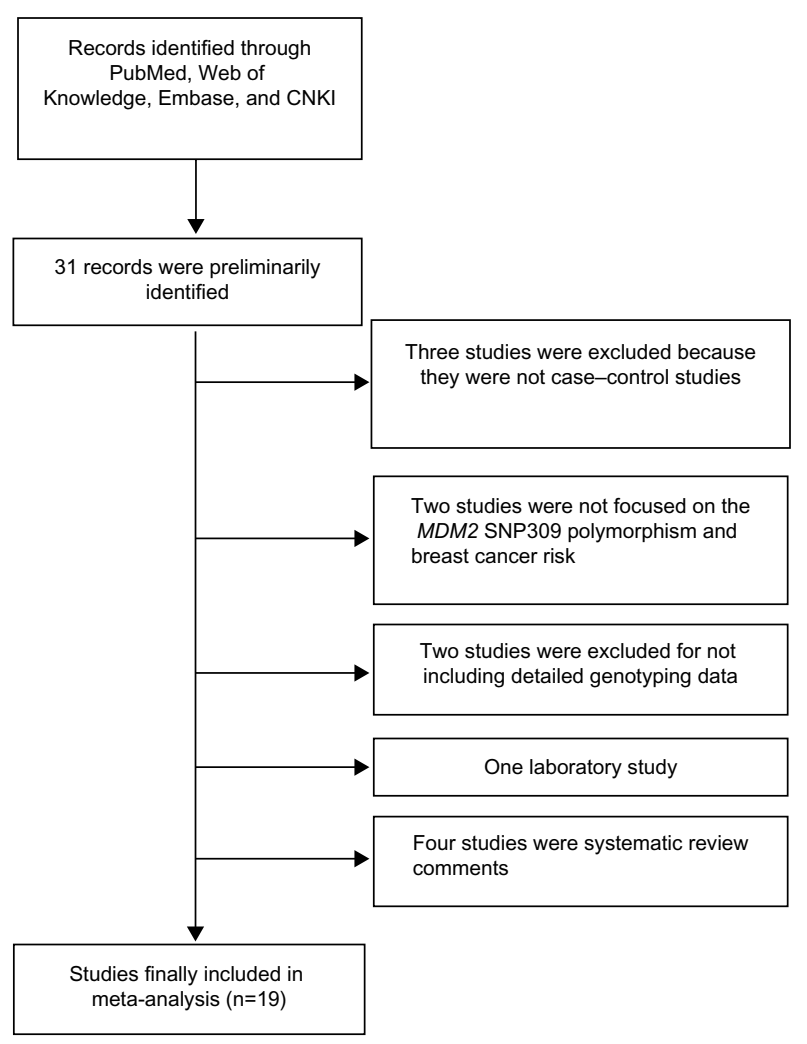

Figure I Flow chart of study selection.

Abbreviations: CNKI, Chinese National Knowledge Infrastructure; MDM2, mouse double minute 2 homolog. and breast cancer risk. Two studies were excluded because there was no detailed genotyping data. One was a laboratory study, and the rest of the four studies were systematic review comments. Finally, 19 studies on MDM2 rs 2279744 genotypes and breast cancer risk were identified, including a total of 7,815 breast cancer cases and 8,677 controls. ${ }^{16-34}$ The characteristics of the included studies are listed in Table 1.

Among the eligible studies, ten studies were based on Caucasian backgrounds which were carried out in the US, UK, Germany, the Netherlands, Finland, Sweden, Israel, and the Czech Republic. Seven were based on Asian ethnicities which were carried out in People's Republic of China, India, Singapore, and Saudi Arabia. Two included African ethnicities, while two studies included individuals with mixed ethnic descent. Breast cancers were confirmed by histology or pathology in most studies. Moreover, controls were mainly matched in age, of which twelve were population-based and seven were hospital-based.

\section{Meta-analysis results}

The main results of this meta-analysis are listed in Table 2. As shown in Figure 2, the variant heterozygote (TG) and homozygote $(\mathrm{GG})$ were associated with breast cancer risk in the overall population (TG vs TT: OR $=1.10,95 \%$ $\mathrm{CI}=1.04-1.17, P=0.001, P=0.23$ for the heterogeneity test; GG vs TT: $\mathrm{OR}=1.09,95 \% \mathrm{CI}=1.00-1.19, P=0.04, P_{\text {het }}=0.07$ ). However, there were no significant associations between the MDM2 rs 2279744 polymorphism and breast cancer risk in other genotype distributions ( $\mathrm{G}$ allele vs $\mathrm{T}$ allele: $\mathrm{OR}=1.03$, 95\% CI $=0.99-1.08, P=0.11, P_{\text {het }}=0.06$; dominant model TG+GG vs TT: $\mathrm{OR}=1.06,95 \% \mathrm{CI}=1.00-1.12, P=0.05$, $P_{\text {het }}=0.007$; recessive model GG vs TT + TG: OR $=1.02,95 \%$ $\left.\mathrm{CI}=0.95-1.11, P=0.55, P_{\text {het }}=0.50\right)$.

Ten articles, including 5,378 cases and 5,944 controls, were used to investigate the association of the MDM2 rs 2279744 polymorphism with breast cancer susceptibility in Caucasians. The results showed that the MDM2 rs 2279744 polymorphism was associated with breast cancer risk in only one genotype (TG vs TT: OR $=1.09,95 \% \mathrm{CI}=1.00-1.18$, $\left.P=0.04, P_{\text {het }}=0.37\right)$, but no associations in other genetic models (G vs T: $\mathrm{OR}=1.03,95 \% \mathrm{CI}=0.97-1.09, P=0.30, P_{\text {het }}=0.60$; GG vs TT: $\mathrm{OR}=1.10,95 \% \mathrm{CI}=0.98-1.23, P=0.11, P_{\text {het }}=0.59$; TG+GG vs TT: $\mathrm{OR}=1.03,95 \% \mathrm{CI}=0.95-1.11, P=0.52$, $P_{\text {het }}=0.08$; GG vs TT+TG: OR $=1.04,95 \% \mathrm{CI}=0.93-1.16$, $\left.P=0.47, P_{\text {het }}=0.48\right)$.

Seven articles, including 1,736 cases and 1,973 controls, were used to evaluate the relationship between the MDM2 rs 2279744 polymorphism and breast cancer susceptibility in 
Table I Characteristics of the studies included in the meta-analysis

\begin{tabular}{|c|c|c|c|c|c|c|}
\hline First author & Year & Country & Ethnicity & $\begin{array}{l}\text { Study } \\
\text { design }\end{array}$ & $\begin{array}{l}\text { Genotyping } \\
\text { method }\end{array}$ & $\begin{array}{l}\text { Total sample size } \\
\text { (Case/control) }\end{array}$ \\
\hline Boersma et $\mathrm{al}^{16}$ & 2006 & USA & $\begin{array}{l}\text { Caucasian } \\
\text { African-American }\end{array}$ & $\mathrm{CC}$ & PCR & $290 / 314$ \\
\hline Campbell et al ${ }^{17}$ & 2006 & UK & Caucasian & $\mathrm{CC}$ & PCR & $35 \mathrm{I} / 258$ \\
\hline Millikan et al ${ }^{18}$ & 2006 & USA & $\begin{array}{l}\text { Caucasian } \\
\text { African-American }\end{array}$ & $\mathrm{CC}$ & PCR-RFLP & $2,037 / I, 8 \mid 3$ \\
\hline Petenkaya et $\mathrm{a}^{19}$ & 2006 & Turkey & Mixed & $\mathrm{CC}$ & PCR-RFLP & $223 / 149$ \\
\hline Ma et $\mathrm{al}^{21}$ & 2006 & $\begin{array}{l}\text { People's Republic } \\
\text { of China }\end{array}$ & Asian & $\mathrm{CC}$ & PCR & $366 / 605$ \\
\hline Wilkening et $\mathrm{a}^{20}$ & 2006 & Germany & Caucasian & $\mathrm{CC}$ & qPCR & $549 / 1,065$ \\
\hline Wasielewski et $\mathrm{a}^{22}$ & 2007 & The Netherlands & Caucasian & $\mathrm{CC}$ & PCR & $343 / 126$ \\
\hline Cox et $\mathrm{al}^{23}$ & 2007 & America & Mixed & $\mathrm{CC}$ & PCR-RFLP & $|, 5| 9 / 2,27 \mid$ \\
\hline Lum et $\mathrm{al}^{24}$ & 2008 & Singapore & Asian & $\mathrm{CC}$ & PCR & $402 / 128$ \\
\hline Singh et $\mathrm{al}^{25}$ & 2008 & India & Asian & $\mathrm{CC}$ & qPCR & $104 / 105$ \\
\hline Paulin et $\mathrm{a}^{26}$ & 2008 & England & Caucasian & $\mathrm{CC}$ & qPCR & $299 / 275$ \\
\hline Krekac et al ${ }^{27}$ & 2008 & Czech Republic & Caucasian & $\mathrm{CC}$ & PCR-RFLP & $158 / 149$ \\
\hline Yarden et a $\left.\right|^{28}$ & 2008 & Israel & Caucasian & $\mathrm{CC}$ & $\mathrm{qPCR}$ & $187 / 138$ \\
\hline Lang et $\mathrm{al}^{29}$ & 2009 & Sweden & Caucasian & $\mathrm{CC}$ & PCR-RFLP & $123 / 146$ \\
\hline Sun et $a^{30}$ & 2009 & $\begin{array}{l}\text { People's Republic } \\
\text { of China }\end{array}$ & Asian & $\mathrm{CC}$ & PCR-RFLP & $124 / 97$ \\
\hline Koh et $\mathrm{a}^{31}$ & 2011 & Singapore & Asian & $\mathrm{CC}$ & qPCR & $385 / 614$ \\
\hline Leu et $\mathrm{al}^{32}$ & 2011 & $\begin{array}{l}\text { People's Republic } \\
\text { of China }\end{array}$ & Asian & $\mathrm{CC}$ & $\mathrm{PCR}$ & $255 / 324$ \\
\hline Knappskog et $\mathrm{al}^{33}$ & 2011 & WEC, Finland & Caucasian & $\mathrm{CC}$ & PCR-RFLP/Taqman & $|, 973 / 2,5| 8$ \\
\hline Alshatwi et $\mathrm{al}^{34}$ & 2012 & Saudi Arabia & Asian & $\mathrm{CC}$ & PCR & $100 / 100$ \\
\hline
\end{tabular}

Abbreviations: CC, case-control; PCR, polymerase chain reaction; RFLP, restriction fragment length polymorphism; WEC, Western European countries including the UK, the Netherlands, and Norway; qPCR, quantitative PCR.

Table 2 Meta-analysis of the association between the MDM2 rs 2279744 polymorphism and breast cancer risk

\begin{tabular}{|c|c|c|c|c|c|c|}
\hline \multirow[t]{2}{*}{ Comparisons } & \multirow[t]{2}{*}{ OR } & \multirow[t]{2}{*}{$95 \% \mathrm{Cl}$} & \multirow[t]{2}{*}{$P$-value } & \multicolumn{2}{|c|}{ Heterogeneity } & \multirow{2}{*}{$\begin{array}{l}\text { Effects } \\
\text { model }\end{array}$} \\
\hline & & & & $I^{2}$ & $P$-value & \\
\hline G vs $T$ & 1.03 & $0.99-1.08$ & 0.11 & $36 \%$ & 0.06 & Random \\
\hline Asian & 1.12 & $1.02-1.23$ & 0.02 & $54 \%$ & 0.04 & Random \\
\hline Eastern Asian & 1.07 & $0.97-1.19$ & 0.17 & $65 \%$ & 0.02 & Random \\
\hline Caucasian & 1.03 & $0.97-1.09$ & 0.30 & $0 \%$ & 0.60 & Fixed \\
\hline African & 1.15 & $0.94-1.42$ & 0.17 & $37 \%$ & 0.21 & Fixed \\
\hline GG vs TT & 1.09 & $1.00-1.19$ & 0.04 & $35 \%$ & 0.07 & Random \\
\hline Asian & 1.29 & $1.06-1.56$ & 0.01 & $55 \%$ & 0.04 & Random \\
\hline Eastern Asian & 1.25 & $1.01-1.54$ & 0.04 & $55 \%$ & 0.06 & Random \\
\hline Caucasian & 1.10 & $0.98-1.23$ & 0.11 & $0 \%$ & 0.59 & Fixed \\
\hline African & 0.75 & $0.39-1.47$ & 0.40 & $0 \%$ & 0.57 & Fixed \\
\hline TG vs TT & 1.10 & $1.04-1.17$ & 0.001 & $18 \%$ & 0.23 & Fixed \\
\hline Asian & 1.36 & $1.15-1.60$ & 0.0004 & $0 \%$ & 0.45 & Fixed \\
\hline Eastern Asian & 1.37 & I.15-1.64 & 0.0006 & $20 \%$ & 0.29 & Fixed \\
\hline Caucasian & 1.09 & $1.00-1.18$ & 0.04 & $8 \%$ & 0.37 & Fixed \\
\hline African & 1.31 & $1.03-1.66$ & 0.03 & $60 \%$ & 0.11 & Fixed \\
\hline TG+GG vs TT & 1.06 & $1.00-1.12$ & 0.05 & $50 \%$ & 0.007 & Random \\
\hline Asian & 1.21 & $|.03-1.4|$ & 0.02 & $49 \%$ & 0.07 & Random \\
\hline Eastern Asian & 1.19 & $|.00-| .4 \mid$ & 0.05 & $58 \%$ & 0.05 & Random \\
\hline Caucasian & 1.03 & $0.95-1.11$ & 0.52 & $42 \%$ & 0.08 & Random \\
\hline African & 1.24 & $0.99-1.56$ & 0.07 & $53 \%$ & 0.14 & Fixed \\
\hline GG vs TT+TG & 1.02 & $0.95-1.11$ & 0.55 & $0 \%$ & 0.50 & Fixed \\
\hline Asian & 1.04 & $0.89-1.21$ & 0.63 & $38 \%$ & 0.14 & Fixed \\
\hline Eastern Asian & 1.00 & $0.85-1.18$ & 0.99 & $16 \%$ & 0.31 & Fixed \\
\hline Caucasian & 1.04 & $0.93-1.16$ & 0.47 & $0 \%$ & 0.48 & Fixed \\
\hline African & 0.72 & $0.37-1.40$ & 0.33 & $0 \%$ & 0.52 & Fixed \\
\hline
\end{tabular}

Abbreviations: $\mathrm{Cl}$, confidence interval; OR, odds ratio; vs, versus; G, Guanine; T, Thymine; GG vs TT, homozygous genetic model; TG vs TT, allele contrast genetic model; TG+GG vs TT, dominant model; GG vs TT+TG, recessive model; MDM2, mouse double minute 2 homolog. 


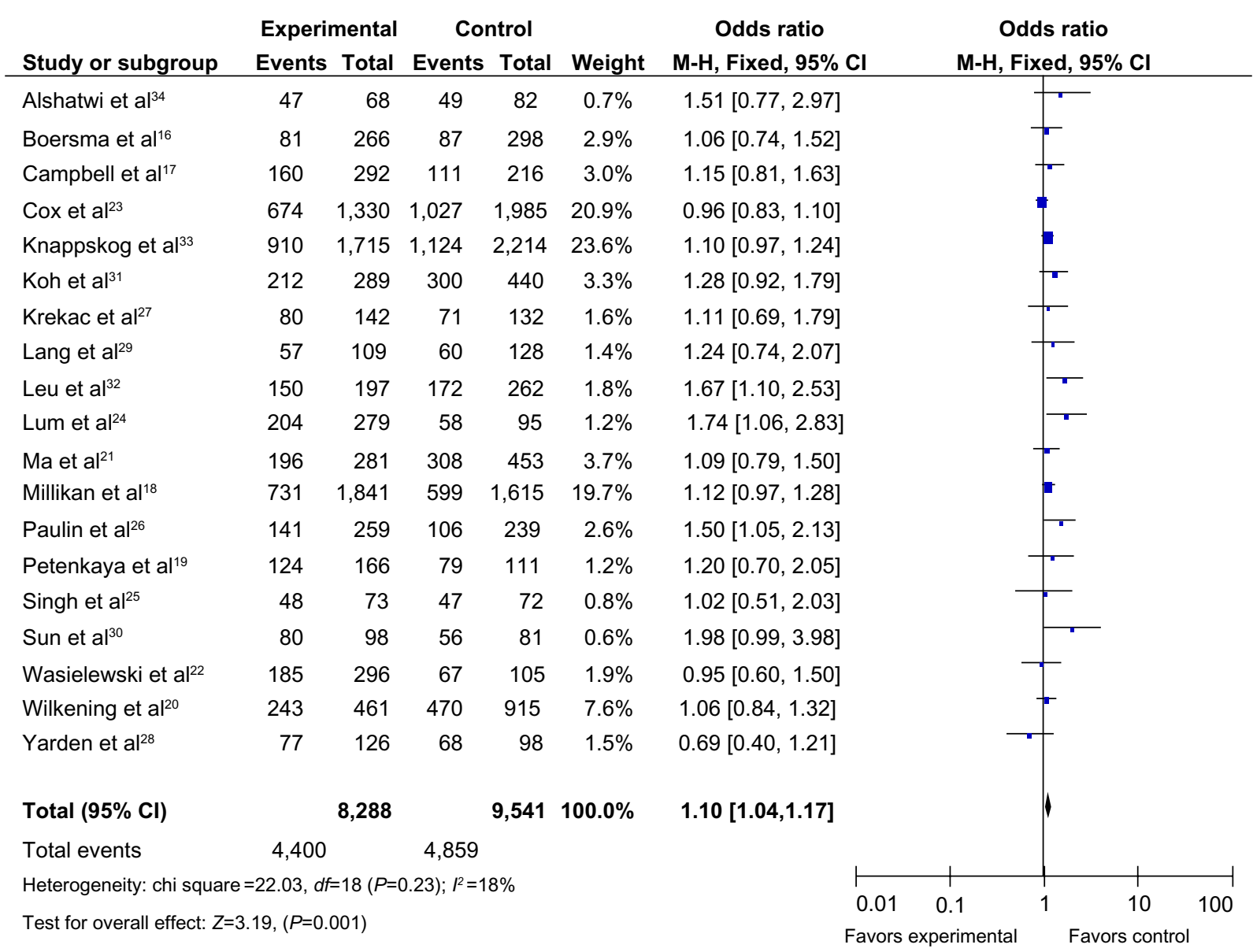

Figure 2 Forest plots of the MDM2 rs 2279744 polymorphism and breast cancer risk in the overall population (TG vs TT).

Notes: The squares and horizontal lines correspond to the study specific OR and $95 \% \mathrm{Cl}$. The area of the squares reflects the weight (inverse of the variance). The diamond represents the summary OR and $95 \% \mathrm{Cl}$.

Abbreviations: $\mathrm{Cl}$, confidence interval; OR, odds ratio; $\mathrm{df}$, degrees of freedom; $\mathrm{M}-\mathrm{H}$, Mantel-Haenszel; MDM2, mouse double minute 2 homolog.

Asians. In the subgroup analysis by ethnicity, in the Asian population, the results revealed significant associations between the MDM2 rs 2279744 polymorphism and breast cancer in four genetic models (G vs T: OR $=1.12,95 \%$ $\mathrm{CI}=1.02-1.23, P=0.02, P_{\text {het }}=0.04$; GG vs TT: $\mathrm{OR}=1.29$, $95 \% \mathrm{CI}=1.06-1.56, P=0.01, P_{\text {het }}=0.04 ;$ TG vs TT: OR $=1.36$, $95 \% \mathrm{CI}=1.15-1.60, P=0.0004, P_{\mathrm{het}}=0.45 ; \mathrm{TG}+\mathrm{GG}$ vs TT: $\left.\mathrm{OR}=1.21,95 \% \mathrm{CI}=1.03-1.41, P=0.02, P_{\text {het }}=0.07\right)$, but not in the recessive model (GG vs TT+TG: OR $=1.04,95 \%$ $\left.\mathrm{CI}=0.89-1.21, P=0.63, P_{\text {het }}=0.14\right)$. A forest plot of the results is shown in Figure 3.

It is somewhat strange to pool data from Chinese individuals with Arab individuals since these are two very different populations. Therefore, we pooled the data for Eastern Asians (People's Republic of China and Singapore). These results also showed association between rs 2279744 and breast cancer risk (GG vs TT: $\mathrm{OR}=1.25,95 \% \mathrm{CI}=1.01-1.54, P=0.04, P_{\text {het }}=0.06$; TG vs TT: $\mathrm{OR}=1.37,95 \% \mathrm{CI}=1.15-1.64, P=0.0006$, $P_{\text {het }}=0.29$; TG $+\mathrm{GG}$ vs TT: $\mathrm{OR}=1.19,95 \% \mathrm{CI}=1.00-1.41$, $P=0.05, P_{\text {het }}=0.05$ ).
There were only two articles, including 932 cases and 858 controls, that were used to evaluate the relationship between the MDM2 rs 2279744 polymorphism with breast cancer susceptibility in Africans. As shown in Figure 4, the variant heterozygote (TG) seemed to be associated with breast cancer risk in Africans (TG vs TT: OR $=1.31$, $95 \% \mathrm{CI}=1.03-1.66, P=0.03, P=0.11$ for heterogeneity test). However, there were no significant associations in the other genetic models in Africans ( $\mathrm{G}$ vs T: OR $=1.15,95 \% \mathrm{CI}$ $=0.94-1.42, P=0.17, P_{\text {het }}=0.21 ;$ GG vs TT: OR $=0.75,95 \%$ $\mathrm{CI}=0.39-1.47, P=0.40, P_{\mathrm{het}}=0.57 ; \mathrm{TG}+\mathrm{GG}$ vs TT: $\mathrm{OR}=1.24$, $95 \% \mathrm{CI}=0.99-1.56, P=0.07, P_{\text {het }}=0.14 ; \mathrm{GG}$ vs TT + TG: OR $\left.=0.72,95 \% \mathrm{CI}=0.37-1.40, P=0.33, P_{\text {het }}=0.53\right)$.

\section{Publication bias}

Begg's funnel plot and Egger's test were performed to assess publication bias. As shown in Figure 5, the funnel plots did not reveal any obvious asymmetry in all genotypes in the overall population, and the results of Egger's test revealed no publication bias $(P>0.05)$. 


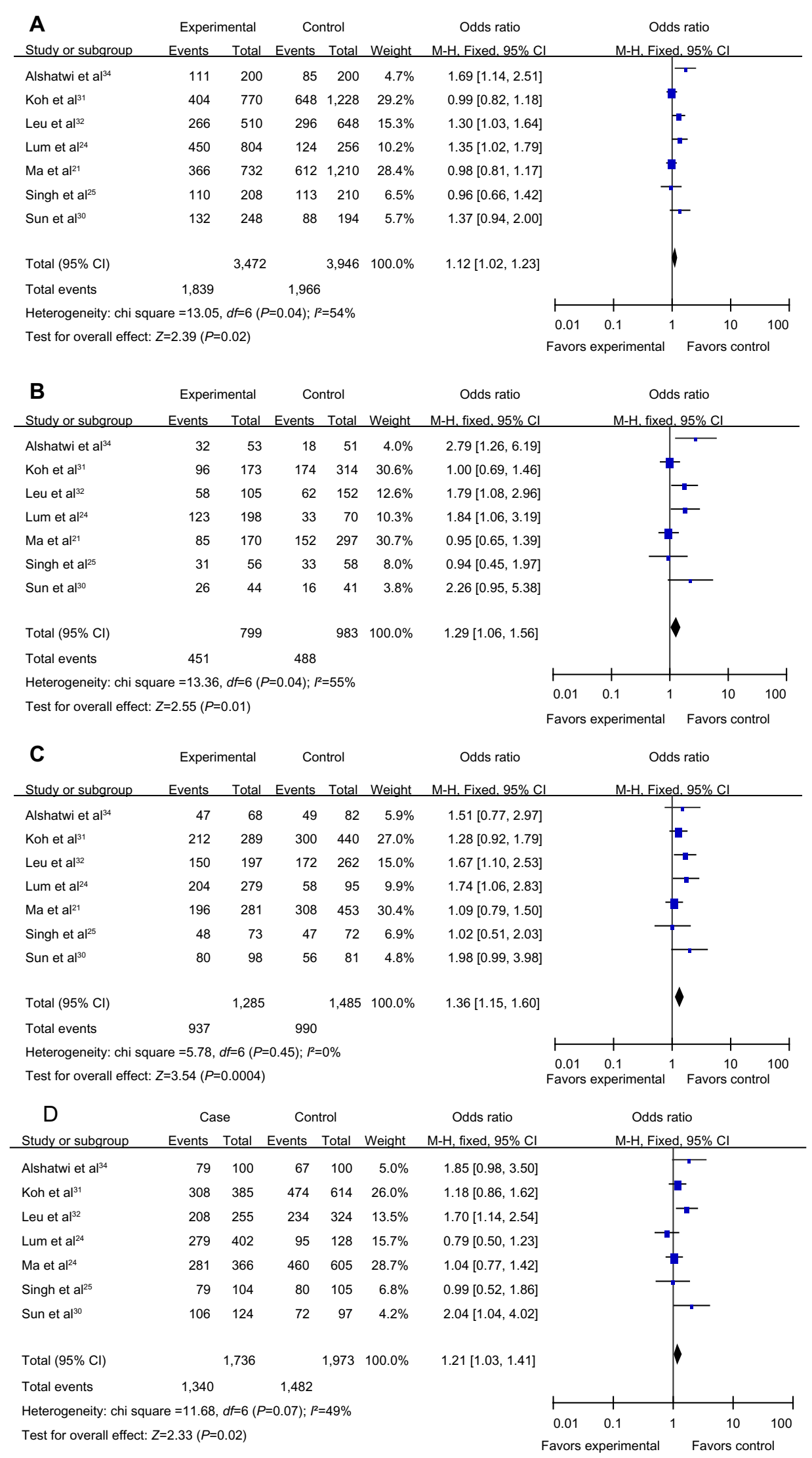

Figure 3 Forest plots showing the relationship between the MDM2 rs 2279744 polymorphism and breast cancer risk in the Asian subgroup; (A) G vs T; (B) GG vs TT; (C) TG vs TT; (D) TG+GG vs TT.

Abbreviations: $\mathrm{Cl}$, confidence interval; OR, odds ratio; $d f$, degrees of freedom; M-H, Mantel-Haenszel; G, Guanine; T, Thymine; GG vs TT, homozygous genetic model; TG vs TT, allele contrast genetic model; TG+GG vs TT, dominant model; GG vs TT+TG, recessive model; MDM2, mouse double minute 2 homolog. 


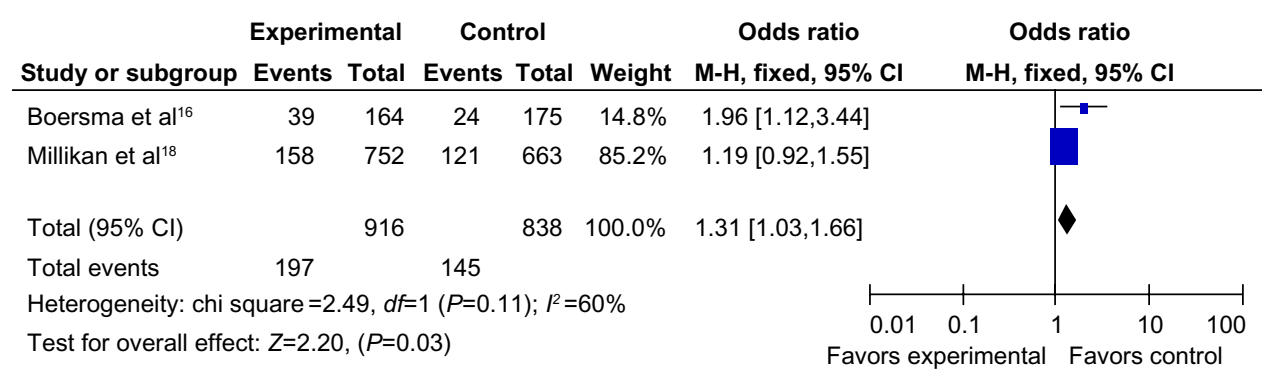

Figure 4 Forest plot showing the relationship between the MDM2 rs 2279744 polymorphism and breast cancer risk in the African subgroup (TG vs TT). Abbreviations: $\mathrm{Cl}$, confidence interval; OR, odds ratio; df, degrees of freedom; $\mathrm{M}-\mathrm{H}$, Mantel-Haenszel; vs, versus; MDM2, mouse double minute 2 homolog; TG vs TT, allele contrast genetic model.

\section{Discussion}

Multiple lines of evidence support an important role for genetics in determining risk for cancer, and association studies are appropriate for searching susceptibility genes involved in cancer. ${ }^{35}$ It has been suggested that SNPs are the most common sources of human genetic variation and they may contribute to an individual's susceptibility to cancer. ${ }^{36-38}$

In recent years, interest in the genetic susceptibility to cancers has led to growing attention to the study of gene polymorphisms involved in tumorigenesis. Some genetic polymorphisms of genes have been implicated to alter cancer susceptibility. ${ }^{36,38,39}$ A previous study indicates that MDM2 SNP309 serves as a tumor susceptibility marker, and that there is an association between MDM2 SNP309 and p53 Arg72Pro regarding tumor susceptibility. ${ }^{38} \mathrm{In}$ vitro analyses revealed that SNP309G enhances Sp1 promoter binding, while SNP285C strongly lessens this binding. ${ }^{33}$ Comparing MDM2 promoter status among different cohorts of breast cancer patients versus healthy controls, SNP285C reduced the risk of breast cancer $(\mathrm{OR}=0.79 ; 95 \% \mathrm{CI}=0.62-1.00)$ among $\mathrm{SNP} 309 \mathrm{G}$ carriers. ${ }^{33}$

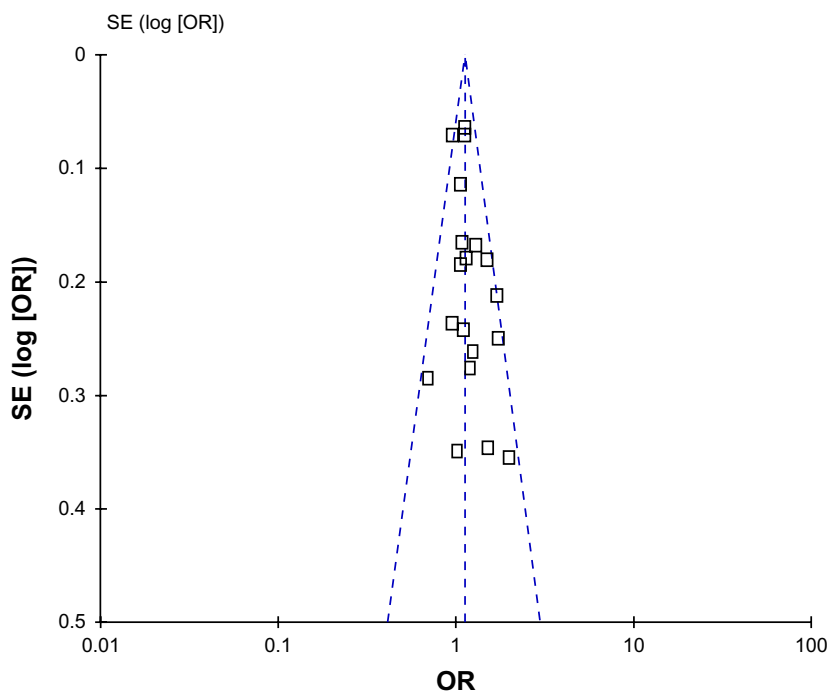

Figure 5 Funnel plot assessing evidence of publication bias from 19 studies (TG vs TT). Abbreviations: SE, standard error; OR, odds ratio; TG vs TT, allele contrast genetic model.
In a large collaborative study by the Breast Cancer Association Consortium, there was no evidence for either an increase in risk or an earlier age at onset of breast cancer in carriers of MDM2 rs $2279744 .{ }^{14}$ In the previous study, G-allele of $M D M 2$ rs 2279744 accelerated breast cancer tumorigenesis via an estrogen-signaling pathway. ${ }^{40}$ Meanwhile, in a Japanese study including 557 primary breast cancer patients, although the $\mathrm{T} / \mathrm{T}$ genotype tended to be associated with better disease-free survival compared to other genotypes of rs 2279744, this association did not achieve significance $(P>0.05)$, and no statistically significant correlation was found between prognosis and MDM2 rs 2279744 genotype. ${ }^{41}$ The MDM2 promoter rs 2279744 polymorphism influences long-term survival among patients receiving paclitaxel for large primary breast cancers. ${ }^{42}$

The relationship between the rs 2279744 polymorphism and cancer was inconsistent. Two recent meta-analyses on colorectal and ovarian cancer showed no significant association between the MDM2 rs 2279744 polymorphism and colorectal (or ovarian) cancer risk in total population analysis, respectively. ${ }^{15,43}$ In the subgroup meta-analysis by ethnicity, a significantly increased risk was observed among Asians in colorectal cancer. ${ }^{15}$ However, in ovarian cancer, a negative association was shown in the Asian subgroup. ${ }^{43}$ Two large studies in the US ${ }^{18,23}$ and other studies in UK, ${ }^{17}$ Turkish, ${ }^{19}$ and Chinese ${ }^{21}$ breast cancer cases found no evidence for an increased risk of breast cancer. However, in the study based on the Chinese/Singapore population, the MDM2 rs $2279744 \mathrm{G}$ allele increased risk while the $\mathrm{T}$ allele was associated with earlier onset age of sporadic breast cancers. ${ }^{24}$ In this meta-analysis, we found that those with the rs 2279744 TG genotype had a significantly increased risk of breast cancer (TG vs TT: OR $=1.10,95 \% \mathrm{CI}=1.04-1.17$, $P=0.001, P_{\text {het }}=0.23$ ).

A previous meta-analysis reported that the association between MDM2 SNP309 and breast cancer is influenced by race. MDM2 SNP309 represents a risk factor for breast cancer in Chinese women but not in non-Chinese women. ${ }^{44}$ 
In our subgroup meta-analysis based on ethnicity, compared with the $\mathrm{T}$ allele, a significantly increased risk of breast cancer is associated with the G allele in Asian. Furthermore, compared with the TT genotype, a significantly increased risk of breast cancer is associated with the TG genotype, GG genotype, and the combined TG/GG genotypes subgroup. In the Caucasian subgroup, rs 2279744 was associated with breast cancer risk in only one genotype (TG vs TT: OR =1.09, $95 \% \mathrm{CI}=1.00-1.18, P=0.04, P_{\text {het }}=0.37$ ). Our results indicate that ethnicity may be a main factor on the effects of the polymorphic alleles. It was partially in line with the results of Economopoulos and Sergentanis. ${ }^{44}$

In the subgroup analysis, we also found that the TG genotype was associated with a significantly increased risk of breast cancer in African individuals. Unfortunately, there were only two studies involved. In addition, as individuals in these two studies were African-American, environmental factors need to be eliminated, as previous findings have shown implications for reconciling differences in the estimates of population growth parameters made using African and African-American populations. ${ }^{45}$ Further investigations on a large scale on African populations are needed to verify this result.

Some limitations in this meta-analysis must be addressed. First, in the subgroup analyses, the numbers of Asians and Africans were relatively low, with inadequate statistical power to explore the exact correlation. Second, only published studies in English were included in this meta-analysis; some ongoing studies and data published in other languages were not pooled, which may have skewed the results. Third, since limited studies were from Africans, large-scale multicenter epidemiological studies based on Africans with different environmental background are urgently needed. Moreover, further studies estimating the effect of gene-gene and geneenvironment interactions may eventually provide a comprehensive understanding of the association between the MDM2 rs 2279744 polymorphism and breast cancer risk.

\section{Conclusion}

In summary, the present meta-analysis provides evidence of the association between MDM2 rs 2279744 polymorphism and breast cancer risk. The rs 2279744 polymorphism plays an important role in breast cancer, especially in Asians.

\section{Acknowledgments}

This study was supported by the National Natural Science Foundation, People's Republic of China (No 81274136), the International Cooperative Project of Shaanxi province, People's Republic of China (No 2013KW-32-01), and the
Specialized Research Fund of the Second Affiliated Hospital of Xi'an Jiaotong University, People's Republic of China (RC [GG] 201203).

\section{Disclosure}

The authors report no conflicts of interest in this work.

\section{References}

1. Siegel R, Naishadham D, Jemal A. Cancer statistics, 2013. CA Cancer J Clin. 2013;63(1):11-30.

2. Bradbury AR, Olopade OI. Genetic susceptibility to breast cancer. Rev Endocr Metab Disord. 2007;8(3):255-267.

3. Wolff MS, Weston A. Breast cancer risk and environmental exposures. Environ Health Perspect. 1997;105:891-896.

4. Hulka BS, Moorman PG. Breast cancer: hormones and other risk factors. Maturitas. 2008;61(1-2):203-213; discussion 213.

5. Levine AJ. p53, the cellular gatekeeper for growth and division. Cell. 1997;88(3):323-331.

6. Momand J, Zambetti GP, Olson DC, George D, Levine AJ. The mdm-2 oncogene product forms a complex with the $\mathrm{p} 53$ protein and inhibits p53-mediated transactivation. Cell. 1992;69(7):1237-1245.

7. Bartel F, Meye A, Wurl P, et al. Amplification of the MDM2 gene, but not expression of splice variants of MDM2 MRNA, is associated with prognosis in soft tissue sarcoma. Int J Cancer. 2001;95:168-175.

8. Bond GL, Hu W, Bond EE, et al. A single nucleotide polymorphism in the MDM2 promoter attenuates the p53 tumor suppressor pathway and accelerates tumor formation in humans. Cell. 2004;119(5):591-602.

9. Rayburn E, Zhang R, He J, Wang H. MDM2 and human malignancies: expression, clinical pathology, prognostic markers, and implications for chemotherapy. Curr Cancer Drug Targets. 2005;5:27-41.

10. Hu Z, Jin G, Wang L, Chen F, Wang X, Shen H. MDM2 promoter polymorphism SNP309 contributes to tumor susceptibility: evidence from 21 case-control studies. Cancer Epidemiol Biomarkers Prev. 2007;16(12):2717-2723.

11. Menin C, Scaini M, De Salvo G, et al. Association between MDM2SNP309 and age at colorectal cancer diagnosis according to p53 mutation status. J Natl Cancer Inst. 2006;98:285-288.

12. Ohmiya N, Taguchi A, Mabuchi N, et al. MDM2 promoter polymorphism is associated with both an increased susceptibility to gastric carcinoma and poor prognosis. J Clin Oncol. 2006;24:4434-4440.

13. Yoon YJ, Chang HY, Ahn SH, et al. MDM2 and p53 polymorphisms are associated with the development of hepatocellular carcinoma in patients with chronic hepatitis B virus infection. Carcinogenesis. 2008;29(6):1192-1196.

14. Schmidt MK, Reincke S, Broeks A, et al. Do MDM2 SNP309 and TP53R72P interact in breast cancer susceptibility? A large pooled series from the breast cancer association consortium. Cancer Res. 2007;67(19):9584-9590.

15. Fu Q, Zhang G, Chen H, Zheng Y, Cheng J. Current evidence on the relationship between SNP309 polymorphism in the MDM2 gene and colorectal cancer risk. Tumour Biol. 2013;34(6):3721-3729.

16. Boersma BJ, Howe TM, Goodman JE, et al. Association of breast cancer outcome with status of p53 and MDM2 SNP309. J Natl Cancer Inst. 2006;98:911-919.

17. Campbell IG, Eccles DM, Choong DY. No association of the MDM2 SNP309 polymorphism with risk of breast or ovarian cancer. Cancer Lett. 2006;240:195-197.

18. Millikan RC, Heard K, Winkel S, et al. No association between the MDM2-309 T/G promoter polymorphism and breast cancer in African-Americans or Whites. Cancer Epidemiol Biomarkers Prev. 2006; 15:175-177.

19. Petenkaya A, Bozkurt B, Akilli-Ozturk O, Kaya HS, Gur-Dedeoglu B, Yulug IG. Lack of association between the MDM2-309 polymorphism and breast cancer risk. Anticancer Res. 2006;26:4975-4977. 
20. Wilkening S, Bermejo JL, Burwinkel B, et al. The single nucleotide polymorphism IVS1+309 in mouse double minute 2 does not affect risk of familial breast cancer. Cancer Res. 2006;66(2):646-648.

21. $\mathrm{Ma} \mathrm{H}, \mathrm{Hu} \mathrm{Z}$, Zhai X, et al. Polymorphisms in the MDM2 promoter and risk of breast cancer: a case-control analysis in a Chinese population. Cancer Lett. 2006;240:261-267.

22. Wasielewski M, Nagel JH, Brekelmans C, et al. MDM2 SNP309 accelerates familial breast carcinogenesis independently of estrogen signaling. Breast Cancer Res Treat. 2007;104:153-157.

23. Cox DG, Deer D, Guo Q, et al. The p53 Arg 72 Pro and MDM2-309 polymorphisms and risk of breast cancer in the nurses' health studies. Cancer Causes Control. 2007;18(6):621-625.

24. Lum SS, Chua HW, Li H, et al. MDM2 SNP309 G allele increases risk but the $\mathrm{T}$ allele is associated with earlier onset age of sporadic breast cancers in the Chinese population. Carcinogenesis. 2008;29(4):754-761.

25. Singh V, Rastogi N, Mathur N, Singh K, Singh MP. Association of polymorphism in MDM-2 and p53 genes with breast cancer risk in Indian women. Ann Epidemiol. 2008;18(1):48-57.

26. Paulin FE, O'Neill M, McGregor G, et al. MDM2 SNP309 is associated with high grade node positive breast tumours and is in linkage disequilibrium with a novel MDM2 intron 1 polymorphism. $B M C$ Cancer. 2008;8:281

27. Krekac D, Brozkova K, Knoflickova D, et al. MDM2SNP309 does not associate with elevated MDM2 protein expression or breast cancer risk Oncology. 2008;74(1-2):84-87.

28. Yarden RI, Friedman E, Metsuyanim S, OlenderT, Ben-Asher E, Papa MZ. MDM2 SNP309 accelerates breast and ovarian carci-nogenesis in BRCA1 and BRCA2 carriers of Jewish-Ashkenazi descent. Breast Cancer Res Treat. 2008;111:497-504.

29. Lang A, Palmebäck Wegman P, Wingren S. The significance of MDM2 SNP309 and p53 Arg72Pro in young women with breast cancer. Oncol Rep. 2009;22(3):575-579.

30. Sun YF, Leu JD, Chen SM, Lin IF, Lee YJ. Results based on 124 cases of breast cancer and 97 controls from Taiwan suggest that the single nucleotide polymorphism (SNP309) in the MDM2 gene promoter is associated with earlier onset and increased risk of breast cancer. $B M C$ Cancer. 2009;9:13.

31. Koh WP, Van Den Berg D, Jin A, Wang R, Yuan JM, Yu MC. Combined effects of MDM2 SNP309 and TP53 R72P polymorphisms, and soy isoflavones on breast cancer risk among Chinese women in Singapore. Breast Cancer Res Treat. 2011;130(3):1011-1019.

32. Leu JD, Wang CY, Tsai HY, Lin IF, Chen RC, Lee YJ. Involvement of p53 R72P polymorphism in the association of MDM2-SNP309 with breast cancer. Oncol Rep. 2011;25(6):1755-1763.
33. Knappskog S, Bjørnslett M, Myklebust LM, et al. The MDM2 promoter SNP285C/309G haplotype diminishes Sp1 transcription factor binding and reduces risk for breast and ovarian cancer in Caucasians. Cancer Cell. 2011;19(2):273-282.

34. Alshatwi AA, Hasan TN, Shafi G, Alsaif MA, Al-Hazzani AA, Alsaif AA. A single-nucleotide polymorphism in the TP53 and MDM-2 gene modifies breast cancer risk in an ethnic Arab population. Fundam Clin Pharmacol. 2012;26(3):438-443.

35. Risch N, Merikangas K. The future of genetic studies of complex human diseases. Science. 1996;273:1516-1517.

36. Wilkening S, Bermejo JL, Hemminki K. MDM2 SNP309 and cancer risk: a combined analysis. Carcinogenesis. 2007;28:2262-2267.

37. Jiang O, Zhou R, Wu D, Liu Y, Wu W, Cheng N. CYP2E1 polymorphisms and colorectal cancer risk: a HuGE systematic review and meta-analysis. Tumor Biol. 2013;34:1215-1224.

38. Wan Y, Wu W, Yin Z, Guan P, Zhou B. MDM2 SNP309, gene-gene interaction, and tumor susceptibility: an updated meta-analysis. $B M C$ Cancer. 2011;11:208.

39. Wo X, Han D, Sun H, et al. MDM2 SNP309 contributes to tumor susceptibility: a meta-analysis. J Genet Genomics. 2011;38(8): $341-350$.

40. Bond GL, Hirshfield KM, KirchhoffT, et al. MDM2 SNP309 accelerates tumor formation in a gender-specific and hormone-dependent manner. Cancer Res. 2006;66:5104-5110.

41. Toyama T, Zhang Z, Nishio M, et al. Association of TP53 codon 72 polymorphism and the outcome of adjuvant therapy in breast cancer patients. Breast Cancer Res. 2007;9(3):R34.

42. Chrisanthar R, Knappskog S, Løkkevik E, et al. Predictive and prognostic impact of TP53 mutations and MDM2 promoter genotype in primary breast cancer patients treated with epirubicin or paclitaxel. PLoS One. 2011;6(4):e19249.

43. Ma YY, Guan TP, Yao HB, et al. The MDM2 309 T.G polymorphism and ovarian cancer risk: a meta-analysis of 1534 cases and 2211 controls. PLoS One. 2013;8(1):e55019.

44. Economopoulos KP, Sergentanis TN. Differential effects of MDM2 SNP309 polymorphism on breast cancer risk along with race: a metaanalysis. Breast Cancer Res Treat. 2010;120(1):211-216.

45. Lohmueller KE, Bustamante CD, Clark AG. The effect of recent admixture on inference of ancient human population history. Genetics. 2010;185(2):611-622.
Therapeutics and Clinical Risk Management

\section{Publish your work in this journal}

Therapeutics and Clinical Risk Management is an international, peerreviewed journal of clinical therapeutics and risk management, focusing on concise rapid reporting of clinical studies in all therapeutic areas, outcomes, safety, and programs for the effective, safe, and sustained use of medicines. This journal is indexed on PubMed Central, CAS,

\section{Dovepress}

EMBase, Scopus and the Elsevier Bibliographic databases. The manuscript management system is completely online and includes a very quick and fair peer-review system, which is all easy to use. Visit http://www.dovepress.com/testimonials.php to read real quotes from published authors. 